\title{
Characterization and phylogenetic analysis of Krüppel-like transcription factor (KLF) gene family in tree shrews (Tupaia belangeri chinensis)
}

\author{
Ming Shao ${ }^{1,2, *}$, Guang-Zhe Ge ${ }^{1,2, *}$, Wen-Jing Liuu, ${ }^{4,1}{ }^{,}$, Ji Xiao ${ }^{4,1}$, Hou-Jun Xia ${ }^{1}$, Yu Fan ${ }^{1}$, \\ Feng Zhao', Bao-Li He ${ }^{3}$, Ceshi Chen ${ }^{1}$ \\ ${ }^{1}$ Key Laboratory of Animal Models and Human Disease Mechanisms of Chinese Academy of Sciences and Yunnan Province, \\ Kunming Institute of Zoology, Chinese Academy of Sciences, Kunming, Yunnan, China \\ ${ }^{2}$ Faculty of Life Science and Technology, Kunming University of Science and Technology, Kunming, Yunnan, China \\ ${ }^{3}$ Department of Laboratory Animal Science, Kunming Medical University, Kunming, Yunnan 650500, China \\ ${ }^{4}$ Medical Faculty, Kunming University of Science and Technology, Kunming, Yunnan, China \\ *These authors contributed equally to this work \\ Correspondence to: Ceshi Chen, email: chenc@mail.kiz.ac.cn
}

Keywords: $K L F$, tree shrew, expression, motif, KLF5

Received: May 06, 2016

Accepted: December 05, 2016

Published: December 10, 2016

\section{ABSTRACT}

Krüppel-like factors (KLFs) are a family of zinc finger transcription factors regulating embryonic development and diseases. The phylogenetics of KLFs has not been studied in tree shrews, an animal lineage with a closer relationship to primates than rodents. Here, we identified 17 KLFs from Chinese tree shrew (Tupaia belangeri chinensis). KLF proteins are highly conserved among humans, monkeys, rats, mice and tree shrews compared to zebrafish and chickens. The CtBP binding site, Sin $3 A$ binding site and nuclear localization signals are largely conserved between tree shrews and human beings. Tupaia belangeri (Tb) KLF5 contains several conserved post-transcriptional modification motifs. Moreover, the mRNA and protein expression patterns of multiple tbKLFs are tissue-specific. TbKLF5, like hKLF5, significantly promotes NIH3T3 cell proliferation in vitro. These results provide insight for future studies regarding the structure and function of the tbKLF gene family.

\section{INTRODUCTION}

Human Krüppel-like factors (hKLFs) belong to a transcription factor family with 17 members containing three highly conserved zinc finger DNA binding domains at their C-terminus $[1,2]$. KLFs play important roles in a diverse array of physiological and pathological cellular processes, including cell proliferation, apoptosis, migration and differentiation [3, 4]. KLFs promote the pluripotent state of embryonic stem cells $[5,6]$, and regulate embryonic and system development, including the cardiovascular [7], respiratory [8], digestive [9], hematological [10], skeleton [11], nervous and immune systems $[12,13]$. Moreover, KLFs participate in tissue formation and remodeling, such as cardiac remodeling $[14,15]$, wound healing [16], placenta development [17], angiogenesis $[18,19]$ and gluconeogenesis [20]. Finally, the alteration of KLFs is involved in a number of diseases, such as cancers [21], cardiovascular diseases [22] and metabolic disorders [23].

The C-terminus of all KLFs contains three tandem $\mathrm{C} 2 \mathrm{H} 2$ zinc finger domains that directly bind to GC-rich sequences, including GC and GT boxes (also known as the CACCC box) in target gene promoters [24]. The three zinc fingers have the consensus sequence:

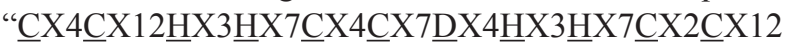

HX3 3 " (Xn: separation of $\mathrm{n}$ residues, C: cysteine, $\mathrm{H}$ : histidine) [2]. Most KLFs contain classical nuclear localization signals (NLS) in their zinc finger (ZF) domains. hKLF1 has two NLSs: NLS1 (275-296) and NLS2 (293-376) [25]. Similarly, hKLF4 and 13 have one NLS within the ZF domain and another one adjacent to the first ZF domain [26, 27]. However, hKLF8 has two nonclassical NLSs; one is in the first two ZF domains in the 
C-terminus, and the other is located in the 151-200 amino acid region within the regulatory N-terminus [28].

Although the KLF gene family has a highly conserved C-terminal DNA binding domain, each KLF has a distinct function in cellular processes because of great variation in its $\mathrm{N}$-terminal sequence that can interact with different transcriptional activators or repressors. For example, KLF3, 5, 8 and 12 harbor the CtBP binding site PVDLS/T and KLF9, 10, 11, 13, 14 and 16 harbor the Sin3A binding site AA/VXXL [4]. A phylogenetic analysis of 17 hKLFs defined their evolutionary history and structural characteristics [4]. The KLF family members were divided into four groups: (1) KLF3, 8 and 12; (2) KLF1, 2, 4-7; (3) KLF9-11, 13, 14 and 16; and (4) KLF15 and 17 [4]. The KLFs in groups 1 and 3 serve as transcriptional repressors by interacting with the corepressors CtBP or $\operatorname{Sin} 3 \mathrm{~A}$, whereas the KLFs in group 2 function as transcriptional activators. Intriguingly, protein interaction motifs were not identified in KLF15 and 17 [4].

KLFs were first identified as an evolutionarily conserved subfamily homologous to Drosophila melanogaster Krüppel protein [29]. KLFs have been studied in various species, including humans [1, 30, 31], murine [32], porcine [33], chicken [34], zebrafish [35], Daphnia [36], and C. elegans [37], as well as metazoans [38]. However, the KLF gene family has never been reported in tree shrews, a valuable and novel animal model for human diseases [39].

Tree shrews (Tupaia belangeri) are widely distributed in Southwest China, Southeast Asia and South Asia and are placed in the order of Scandentia [40]. In recent years, tree shrews have gained increasing attention due to their great potential as an experimental animal model of human diseases [39, 40], such as myopia [41], diabetes [42, 43], depression [44, 45], fatty liver disease [46], viral infection [47-49], hepatocellular carcinoma [50] and breast cancer [51-53]. Whole genome sequencing results demonstrated that the tree shrew lineage has a relatively closer relationship to primates than rodents [54].

Since tree shrews are close to human beings than rodents in evolution, it may serve as a better animal model to study human disease mechanisms [54]. Herein, we elucidated the structural characteristics of $17 \mathrm{KLF}$ factors in tree shrews. This study provides fundamental information on the gene structure and phylogeny of the KLF gene family in the Chinese tree shrews.

\section{RESULTS}

\section{Characterization of tree shrew KLFs}

The tree shrew has a closer relationship to humans than rodents. Because $17 K L F$ genes have been identified in both humans and mice, tree shrews should also have 17 KLFs. We obtained 13 tbKLF coding sequences from the NCBI database and the tbKLF6 coding sequence from the tree shrew database. TbKLF2, 5 and 9 genes were cloned using RT-PCR and sequenced. All 17 tbKLF gene accession numbers are listed in Table 1. The coding regions of tbKLFs are 735 to $1500 \mathrm{bp}$ in length and encode 245 to 500 amino acid residues.

\section{Tree shrew KLFs are evolutionarily conserved}

We sought to define the amino acid sequence similarity among tree shrew, human and mouse KLFs. The whole amino acid similarities between tree shrew and human KLFs range from $41.87 \%$ to $98.51 \%$. TbKLF3-7, 9, 10 and 12 proteins show greater than $90 \%$ identity to their human orthologs. However, tbKLF13, 14, 16 and 17 only share $<60 \%$ similarity (Table 2 ). Consistently, the full KLF amino acid sequences identity between human and mouse range from $42.03 \%$ to $97.02 \%$. Mouse (m) KLF3, 4, 7, 9, 12 and 13 show high similarities $(>90 \%)$, but KLF1, 14 and 17 exhibit low similarities (<70\%). Among these KLFs, mKLF17 protein has the lowest similarity ( $\sim 40 \%)$, as well as tbKLF13 and 16. Overall, tbKLFs and their human homologs have an average $85.56 \%$ and $83.47 \%$ identity on full amino acid and nucleotide sequences respectively, which is slightly higher than those $(83.26 \%$ and $82.3 \%)$ between mouse and their human homologs. Thus, both tbKLFs and mKLFs are homologous to their human corresponding genes. This multigene family is evolutionary conserved, although some members, including tbKLF13, 14, 16, 17, seem to be a little divergent during evolution.

Next, we investigated the phylogenetic relationship of KLFs among different species to track the evolutionary history of tbKLF members. An evolutionary tree was established using the Maximum Likelihood method [56] based on the JTT matrix-based model [59] with KLF amino acid sequences among human, monkey, tree shrew, rat, mouse, chicken and zebrafish (Supplementary Table S2). The bootstrap consensus tree inferred from 1000 replicates is taken to represent the evolutionary history of the taxa analyzed [58].

As the associated taxa clustered together in the booststrap test (1000 replicates) are shown next to the branches. The $K L F$ gene family was divided into three large groups, which were further divided into several subgroups (Figure 1). Group I consists of three subgroups, including KLF1/2/4, KLF5/6/7 and KLF3/8/12. Group II contains three subgroups, including KLF15, KLF10/11 and KLF9/13/14/16. Interestingly, Group III contains only one member, KLF17. In total, the phylogenetic tree shows members of each subgroup are developed from the same ancestral gene during evolution. Different members suffer from different evolution patterns, including convergent evolution and divergent evolution.

For each subgroup members, the evolutionary conservation of KLFs in mammalian including human, monkey, rat and mouse and tree shrew is higher compared 
Table 1: Sequences of Tree shrew KLFs

\begin{tabular}{lccl}
\hline KLFs & Size CDS/cDNA (bp) & Size protein (aa) & Accessionnumber \\
\hline KLF1 & 1083 & 361 & XM_006160997 \\
KLF2 & 1029 & 343 & KT948683 \\
KLF3 & 1032 & 344 & XM_006169246 \\
KLF4 & 1446 & 482 & XM_006150608 \\
KLF5 & 1374 & 458 & KT948685 \\
KLF6 & 852 & 284 & TSDBG00002459 \\
KLF7 & 912 & 304 & XM_006142447 \\
KLF8 & 945 & 315 & XM_006162614 \\
KLF9 & 717 & 239 & KT948684 \\
KLF10 & 1437 & 479 & XM_006145578 \\
KLF11 & 1500 & 500 & XM_006140828 \\
KLF12 & 1209 & 403 & XM_006139823 \\
KLF13 & 744 & 248 & XM_006167284 \\
KLF14 & 954 & 318 & XM_006158848 \\
KLF15 & 1230 & 410 & XM_006169767 \\
KLF16 & 858 & 286 & XM_014585496 \\
KLF17 & 1161 & 387 & XM_006153770 \\
\hline
\end{tabular}

Table 2: Sequence similarities of KLFs from tree shrew, human and mouse

\begin{tabular}{|c|c|c|c|c|c|c|c|c|}
\hline \multirow{3}{*}{$\underset{\text { KLF }}{\text { Human }}$} & \multicolumn{4}{|c|}{ Tree shrew \% homology with human } & \multicolumn{4}{|c|}{ Mouse \% homology with human } \\
\hline & \multicolumn{2}{|c|}{ Zn finger } & \multicolumn{2}{|c|}{ CDS } & \multicolumn{2}{|c|}{ Zn finger } & \multicolumn{2}{|c|}{ CDS } \\
\hline & Nucleotide & Protein & Nucleotide & Protein & Nucleotide & Protein & Nucleotide & Protein \\
\hline HsKLF1 & 90.60 & 94.74 & 79 & 75.55 & 83.95 & 90.12 & 70.06 & 66.75 \\
\hline HsKLF2 & 89.56 & 100 & 87.07 & 73.60 & 85.19 & 96.30 & 82.26 & 87.36 \\
\hline HsKLF3 & 92.18 & 100 & 88.63 & 97.10 & 88.07 & 100 & 86.71 & 95.36 \\
\hline HsKLF4 & 93.83 & 100 & 89.60 & 91.77 & 90.12 & 100 & 86.86 & 90.12 \\
\hline HsKLF5 & 93.42 & 100 & 95.27 & 96.50 & 87.65 & 96.30 & 86.58 & 88.50 \\
\hline HsKLF6 & 92.59 & 100 & 90.85 & 97.53 & 95.47 & 100 & 78.16 & 84.59 \\
\hline HsKLF7 & 97.12 & 100 & 94.19 & 97.69 & 95.47 & 100 & 92.74 & 97.02 \\
\hline HsKLF8 & 93.83 & 98.77 & 79.81 & 80.22 & 93.42 & 100 & 85.37 & 82.73 \\
\hline HsKLF9 & 95.88 & 98.77 & 94.96 & 96.33 & 94.65 & 100 & 94.15 & 96.72 \\
\hline HsKLF10 & 92.18 & 98.77 & 89.95 & 92.29 & 89.71 & 98.77 & 84.13 & 85.42 \\
\hline HsKLF11 & 91.77 & 95.06 & 83.53 & 80.44 & 88.48 & 97.53 & 76.78 & 73.10 \\
\hline HsKLF12 & 94.65 & 100 & 96.86 & 98.51 & 87.24 & 100 & 90.65 & 97.01 \\
\hline HsKLF13 & 91.77 & 95.06 & 55.11 & 41.87 & 95.47 & 98.77 & 88.70 & 91.84 \\
\hline HsKLF14 & 95.88 & 100 & 63.51 & 50.61 & 89.71 & 96.30 & 74.23 & 65.85 \\
\hline HsKLF15 & 94.65 & 100 & 83.13 & 82.93 & 90.12 & 100 & 83.37 & 85.10 \\
\hline HsKLF16 & 90.64 & 94.74 & 68.51 & 42.29 & 86.42 & 92.59 & 81.84 & 85.99 \\
\hline HsKLF17 & 82.72 & 79.01 & 72.47 & 56.71 & 76.54 & 72.84 & 56.57 & 42.03 \\
\hline Average & 92.55 & 97.35 & 83.09 & 79.53 & 89.28 & 96.44 & 82.30 & 83.26 \\
\hline
\end{tabular}


with chicken and zebrafish. Most of KLFs among human, monkey, tree shrew, rat and mouse are closely located on the tree branches, such as KLF4, 7-10, 14 and 15, demonstrating that these species share closer relationship on KLF evolution. Moreover, tbKLF1, 2, 5, 16 and 17 have closer distance to primates than rodents on the inferring evolutionary tree (Figure 1). These data reveal that
tbKLF members are not only evolutionary conserved but also closer to primates than rodent, chicken and zebrafish.

\section{The ZF domains of KLFs in the tree shrew}

KLF proteins are transcription factors acting as activators and/or suppressors. It seems that all KLFs

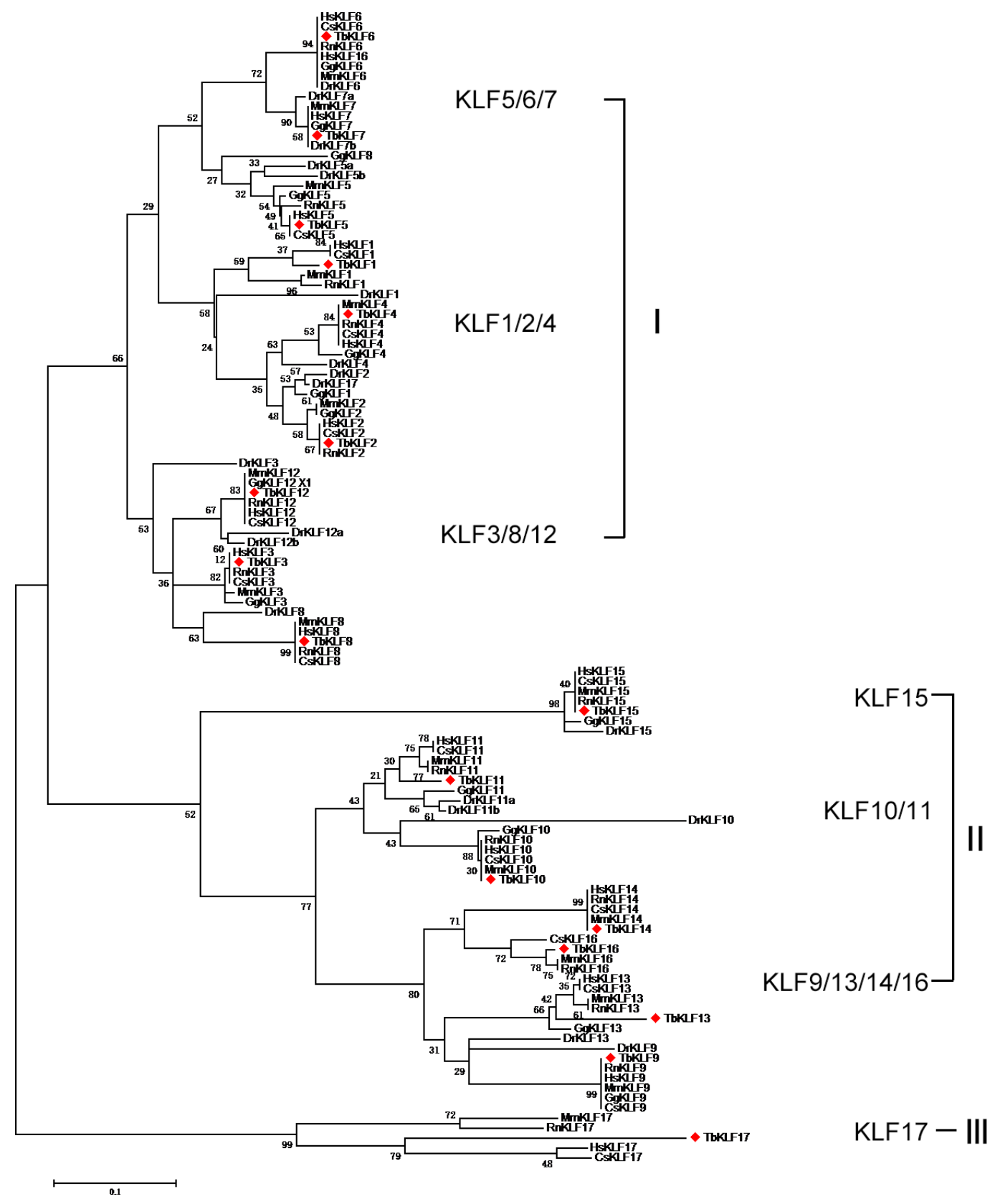

Figure 1: Maximum Likelihood Phylogenetic tree of KLFs from human, monkey, rat, mouse, tree shrew, chicken and zebrafish sequences. The evolutionary history was inferred by using the Maximum Likelihood method based on the JTT matrix-based model. The bootstrap consensus tree inferred from 1000 replicates is taken to represent the evolutionary history of the taxa analyzed. Branches corresponding to partitions reproduced in less than $50 \%$ bootstrap replicates are collapsed. The percentage of replicate trees in which the associated taxa clustered together in the bootstrap test (1000 replicates) are shown next to the branches. The analysis involved 116 amino acid sequences. All positions containing gaps and missing data were eliminated. Evolutionary analyses were conducted in MEGA5. The species acronyms are Hs, Homo sapiens (human); Dr, Danio rerio (zebrafish); Mm, Mus musculus (mouse); Gg, Gallus gallus (chicken); Tb, Tupaia belangeri chinensis (tree shrew); Chlorocebus sabaeus (green monkey); and Rattus norvegicus (rat). 
contain three classical $\mathrm{C} 2 \mathrm{H} 2 \mathrm{ZF}$ domains at their C-terminus, nuclear localization signals (NLS), and transactivation or trans-suppression domains [24, 60]. The ZF domains of KLFs are usually conserved among different species, such as humans and mice (Figure 2). To elucidate whether this conservation is also true for the tree shrew, the ZF domains of 17 tbKLFs were identified (Figure 2). The three $\mathrm{C} 2 \mathrm{H} 2 \mathrm{ZF}$ domains consist of 81 amino acid residues. The first and second $\mathrm{ZF}$ domains consist of 23 amino acid residues, while the last domain has only 21 amino acid residues. Intriguingly, tbKLF1 and 16 do not have the first ZF domain. Because of the critical role of the first zinc-finger domain for sequence specific DNA binding, it is a puzzle for tree shrew to lose this key region during evolution. We deduce that the sequences we obtained are isoforms from alternative splicing.

Zinc finger domains are more highly conserved among different species than the entire coding regions due to the variant $\mathrm{N}$-termini. The alignment results showed that the identity of KLF ZF domains between the tree
Zn finger 1

\begin{tabular}{lllllll}
\hline & & & & & \\
$\mathrm{C}$ & $\mathrm{C}$ & $*$ & $*$ & $*$ & $\mathrm{H}$ & $\mathrm{H}$ \\
- & & & & & &
\end{tabular}

Zn finger 2

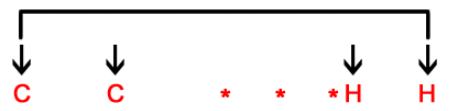

Zn finger 3

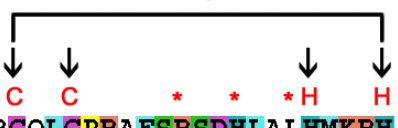
CSYAGCGKTYTK S SHLKAHLRTHTGEK P YHCNWDGCGWKFARSDFLTRHYRKHTGHRP FQCHLCDRAFSRSDHLALHMKRH CDYDGCNKVYTKS SHLKAHRRTHTGEKP YKCTWEGCTWKFARSDELTRHFRKHTGIKPFQCPDCDRS FSRSDHLALHRKRH CDYAGCGKTYTKS SHLKAH LRTHTGEK P YHCDWDGCGWKF ARSDELTRHYRKHTGHRP FQCQKCDRAFSRSDHLALFMKRH CDY P GCTKVYTK S SHLKAHLRTHTGEKP YKCTWEGCDWRF ARSDELTRHYRKHTGAK P FQCGVCNRS FSRSDHLALHMKRH CHFNGCRKVYTKS SHLKAHQRTHTGEK PYRCSWEGCEWRFARSDELTRHFRKHTGAKP FKCSHCDRCFSRSDHLALFMKRH CQFNGCRKVYTKS SHLKAHORTHTGEKP YKCSWEGCEWRFARSDELTRHYRKHTGAK P FKCNHCDRCFSRSDHLALHMKRH CDFAGCSKVYTKS SHLKAHHR I HTGEK P YKCTWDGCSWKFARSDELTRHFRKHTG IKP FRCTDCNRS FSRSDHLS LHRRRH CPYSGCGKVYGKS SHLKAHYRVHT GERP FP CTWPDCLKKF SRSDELTRHYRTHTGEKQFRCPLCEKRFMRSDHLTKHARRH CSHP GCGKTYFK S SHLKAHMRTHTGEK P FS CSWKGCERRFARSDELSRHRRTHTGEKKFA CPMCDRRFMRSDHLTKHARRH CNF P GCRKTY FK S SHLKAHLRTHTGEKP FS CSWDGCDKRF ARSDELSRHRRTHTGEKKFVCP I CDRR FMRSDHLTKHARRF CDFEGCNKVYTK S SHLKAHRRTHTGEK PYKCTWEGCTWKFARSDELTRHYRKHTGVK P FKCADCDRS FSRSDHLALHRRRH CHYAGCEKVYGK S SHLKAHLRTHTGERP FACSWQECSKKF ARSDELARHYRTHT GEKKFGCP I CEKRFMRSDHLTKHARRA CPFPGCTKAYYKS SHLKSHQRTHTGERP FSCDWLDCDKKFTRSDELARHYRTHTGEKRFS CPLCPKQFSRSDHLTKHARRH CTFP GCSKMYTK S SHLKAHLRRHT GEK P FA CTWP GCGWRF SRSDELSRHRRSHS GVK PYQCPVCEKKFARSDHLSKHIKVH (1) CQHENCGKAYTKRSHLVNHORKHTGERPYKCRWEGCAWSF FRSDELGRHMRTHTRYRPHRCELCGROFMRSDHRKOHQTTH CAH P GCGKSYTKS SHLKAHLRTHT GEK P YACTWEGCGWRF ARSDFLTRHYRKHT GQRP FRCQLCPRAFSRSDHLALHMKRH CSYAGCGKTYTK S SHLKAHLRTHTGEKP YHCNWDGCGWK F ARSDELTRHYRKHT GHRPFQCHLCDRAFSRSDHLALHMKRH CDYDGCNKVYTKS SHLKAHRRTHT GEKP YKCTWEGCTWKFARSDELTRHFRKHTGIKP FQCPDCDRS FSRSDHLALHRKRH CDYAGCGKTYTK S SHLKAH LRTHTGEK P YHCDWDGCGWK F ARSDELTRHYRKHTGHRP FQCQKCDRA FSRSDHLALHMKRH CDY P GCTKVYTK S SHLKAHLRTHTGEK PYKCTWEGCDWRFARSDELTRHYRKHTGAK P FQCGVCNRS FSRSDHLALHMKRF CHFNGCRKVYTKS SHLKAHQRTHTGEKP YRCSWEGCEWRFARSDELTRHFRKHTGAKP FKCSHCDRCFSRSDHLALHMKRH CQFNGCRKVYTK S SHLKAHQRTHTGEK P YKCSWEGCEWRFARSDELTRHYRKHTGAK P FKCNHCDRCFSRSDHLALHMKRH CDFAGCSKVYTKS SHLKAHRR IHTGEKPYKCTWDGCSWKFARSDELTRHFRKHTGIKP FRCTDCNRSFSRSDHLSLHRRRH CPYSGCGKVYGKS SHLKAHYRVHT GERP FPCTWP DCLKKF SRSDELTRHYRTHTGEKQFRCPLCEKRFMRSDHLTKHARRH CSHPGCGKTYFK S SHLKAHTRTHTGEK P S CSWKGCERRFARSDELSRHRRTHTGEKKFA CPMCDRRFMRSDHLTKHARRE CSF P GCRKTY FK S SHLKAHLRTHTGEK P FNCSWDGCDKKF ARSDELSRHRRTHTGEKKFVCPVCDRRFMRSDHLTKHARRH CDFEGCNKVYTKS SHLKAHRRTHTGEK PYKCTWEGCTWKFARSDELTRHYRKHTGVK P FKCADCDRS FSRSDHLALHRRRH CHYAGCEKVYGK S SHLKAHLRTHTGERP FACSWQDCNKK FARSDELARHYRTHTGEKKFS CP I CEKRFMRSDHLTKHARRH CPFPGCTKAYYKS SHLKSHQRTHTGERP FSCDWLDCDKKFTRSDELARHYRTHTGEKRFSCPLCPKQFSRSDHLTKHARRH CTF PGCSKMYTK S SHLKAH LRRHT GEK P FACTWP GCGWRF SRSDELSRHRRSHS GVKPYQCPVCEKKFARSDHLSKHIKVH CPF PDCAKAYYKS SHLKSHLRTHTGERP FACDWQGCDKKFARSDELARHHRTHTGEKRFSCPLCSKRFTRSDHLAKHARRH CNYFNCGKAYTKRSHLVSHORKHT GERPYS CNWESCSWSFFRSDELRRHMRYHTRYRPYKCDOCSRFFMRSDHLKOHOKTH CGHEGCGKSYTKS SHLKAHLRTHTGEK PYACSWDGCDWRFARSDELTRHYRKHTGHRPFCCGLCPRAFSRSDHLALHMKRH CSYTNCGKTYTK S SHLKAHLRTHTGEK P YHCNWEGCGWK FARSDELTRHYRKHTGHRPFQCHLCDRAFSRSDHLALHMKRH CDYDGCNKVYTK S SHLKAHRRTHT GEK P YKCTWEGCTWKFARSDELTRHFRKHTGIKP FQCPDCDRSFSRSDHLALHRKRH CDYAGCGKTYTK S SHLKAHLRTHTGEK PYHCDWDGCGWKF ARSDELTRHYRKHTGHRP FQCQKCDRAFSRSDHLALHMKRH CDYNGCTKVYTK S SHLKAHLRTHTGEK PYKCTWEGCDWR FARSDELTRHYRKHTGAK P FQCMVCQRS FSRSDHLALHMKRF CHFNGCRKVYTK S SHLKAHORTHTGEKPYRCSWEGCEWRFARSDELTRHFRKHT GAK P FKCSHCDRCFSRSDHLALHMKRH CQFNGCRKVYTK S SHLKAHQRTHTGEKPYKCSWEGCEWRF ARS DELTRHYRKHTGAK P FK CNHCDRCFSRSDHLALHMKRH CDFAGCSKVYTKS SHLKAHRR I HT GEKP YKCTWDGCSWKFARSDELTRHFRKHTG IKP FRCTDCNRSFSRSDHLS LHRRRH CPYSGCGKVYGKS SHLKAHYRVHTGER F P CTWPDCLKKF SRSDELTRHYRTHTGEKQFRCPLCEKRFMRSDHLTKHARRH CSHP GCGKTY FK S SHLKAHVRTHTGEK P S CSWKGCERRFARSDELSRHRRTHTGEKKFA CPMCDRRFMRSDHLTKHARRF CNF P GCRKTY FKS SHLKAHLRTHTGEK P FTCSWDGCDKK F ARS DELSRHRRTHTGEKKFVCPVCDRRFMRSDHLTKHARRF CDFEGCNKVYTKS SHLKAHRRTHT GEK PYKCTWEGCTWKF ARSDELTRHYRKHTGVK P FKCADCDRS FSRSDHLALHRRRH CHYA GCEKVYGK S SHLKAH LRTHT GERP FACSWQECNKK F ARSDELARHYRTHT GEKKFS CPI CEKRFMRSDHLTKHARRH CSFHGCNKAYYKS SHLKSHQRTHTGERP FSCDWLDCDKKFTRSDELARHYRTHTGEKRFSCPLCPKQFSRSDHLTKHARRH CTF P GCSKMYTK S SHLKAHLRRHTGEKP FA CTWP GCGWRF SRSDELSRHRR SHS GVKPYQCPVCEKKFARSDHLSKHIKVH CPFHGCAKAYYKS SHLKSHLRTHTGERP FACDWP GCDKKFARSDELARHHRTHTGEKRFPCPLCTKRFTRSDHLTKHARRH CTYNSCGKSYTKRSHLVSHQRKHT GVK P FACDWNGCTWKF FRSDELGRHKR I HTRYRPHKCDECDREFMRSDHLRQHKRTH

Figure 2: Amino acid residue alignment of KLF zinc finger domains in tree shrews, mice and humans. Three zinc fingers are indicated above. The cysteine and histidine in the zinc fingers are indicated by a black arrow, and the DNA binding residues are marked with a red asterisk. 
shrew and humans is greater than 90\% (even 100\%) for all KLFs except KLF17 (Table 2). The average homology of nucleotides and proteins between the tree shrew and humans is $92.55 \%$ and $97.35 \%$, respectively. These figures are slightly higher than those between mice and humans. Meanwhile, we built a NJ tree from the zinc finger domains of KLFs among humans, mice and tree shrews (Supplementary Figure S1) with the zinc-finger amino acid sequences collected based on " $\underline{\mathrm{CX}} 4 \underline{\mathrm{CX}} 12 \underline{\mathrm{H} X} 3 \underline{\mathrm{H} X} 7$

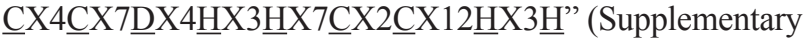
Table S1). The zinc finger domains of tbKLF1, 2, 5 and 17 located in the tree show a closer evolutionary relationship with their orthologs in humans compared to those in mice. Though the zinc-finger domain of KLF17 formed a divergent branch during evolution, it's still conserved among the three different lineages, such as human, tree shrew and mouse (Supplementary Figure S2).

\section{A comparative analysis of $\mathrm{CtBP}$ and $\operatorname{Sin} 3 \mathrm{~A}$ binding sites and NLS in tbKLFs}

In addition to the highly conserved zinc finger domains at their C-termini, we analyzed the relatively variant $\mathrm{N}$-termini containing several functional motifs, including $\mathrm{CtBP}$ binding sites, Sin3 A binding sites and NLS. By aligning the functional motifs of tbKLFs to their orthologs in human, we found that tbKLF3, 8, and 12 have a conserved CtBP binding motif PVDLS/T (Figure 3A). Interestingly, PVDLS/T motifs in KLF3 and 12 are localized at the same regions between the tree shrew and humans, while PVDLS/T motifs in KLF8 are localized at different regions in the tree shrew and humans. A conserved $\operatorname{Sin} 3 \mathrm{~A}$ binding site (AA/VXXL) was identified in hKLF 9-11, 13, 14 and 16. This motif was identified in tbKLF9-11 but not in tbKLF13, 14 and 16 (Figure 3B).

A NLS is essential for transcription factors to localize in the nucleus. We compared the NLS of tbKLFs and hKLFs. hKLF1 contains two NLS. The first one is adjacent to the ZF domain within a highly basic stretch of amino acid residues (Figure 3C). The second one is located within the conserved ZF domain [25]. Sequence alignment results showed that tbKLF1 also has NLS1 and NLS2. Similarly, tbKLF4 and hKLF4 have two NLS that are located at their N-termini and ZF domains [26]. The basic amino acid residues in KLF4 are highly conserved between both species (Figure 3C). In addition, two identified NLS in hKLF13 [27] were identified in tbKLF13 (Figure 3C). Moreover, hKLF8 has been reported to have two non-classical NLS [28]; one is located within a region from 151 to 200 amino acid residues and contains two critical amino acid residues, S165 and K171. Consistently, a motif alignment of KLF8 among tree shrew, human, monkey, rat, mouse and zebrafish sequences show that all species have nearly the same NLS sequence in the $\mathrm{N}$-terminus, especially the two highly conserved residues
(Figure 3C). Not surprisingly, other NLS of tbKLFs in the $\mathrm{ZF}$ domain are conserved as all ZF domains are conserved between tree shrews and humans.

\section{The post-translational modification motifs in TbKLF5}

The tree shrew is an alternative animal model for breast cancer research because it develops spontaneous breast tumors [61]. Thus, we induced breast tumors in tree shrews using different carcinogens, such as DMBA plus MPA and the PyMT oncogene [52]. Our previous work showed that KLF5 is highly expressed in ERa-PR-HER2 triple-negative breast cancer [63, 64]. KLF5 promotes human breast cancer cell proliferation, survival and migration [65]. The human KLF5 protein undergoes different post-translational modifications, including ubiquitination, phosphorylation, acetylation and sumoylation. We analyzed the conservation of modification sites or motifs responsible for recruiting modification enzymes.

Based on the KLF5 CDS phylogenetic tree, tbKLF5 is closer to human and monkey sequences than mouse, rat and chicken sequences (Supplementary Figure S2). Motif alignments showed that tbKLF5 has the conserved CPD (Figure 4A) and PY motifs (Figure 4B) in its transactivation domain. These motifs are responsible for recruiting Fbw7 and WWP1 E3 ubiquitin ligases [66, 67]. These conserved CPD and PY motifs indicate that the tbKLF5 protein may be regulated by Fbw 7 and WWP1 through the ubiquitin-proteasome pathway. In addition, the PKC phosphorylation site S153 [68], the p300 acetylating site K369 [69], and two sumoylation sites K162 and K209 [70] are conserved among tree shrew, human, monkey, mouse, rat and chicken proteins (Figure 4C).

\section{The expression patterns of tbKLFs}

KLFs play important roles in cell stemness, proliferation, survival, migration, and differentiation. Abnormal expression of KLF proteins in different human and mouse tissues can trigger several diseases, including cancers, cardiovascular diseases and metabolic diseases [4]. We sought to determine the relative mRNA and protein expression levels of several KLFs in different tree shrew tissues.

We chose six tbKLF genes, including KLF3, 4, 5, 6,11 and 12 , to examine their mRNA levels in the liver, heart, spleen, lung, kidney, stomach and colon using RTqPCR. Compared to the liver, all of the detected factors have a high mRNA level in the heart (Figure 5). TbKLF3 is relatively highly expressed in the heart, liver, kidney and stomach but lowly expressed in the spleen, lung and colon (Figure 5A). TbKLF4 is just highly expressed in the heart (Figure 5B). TbKLF5 shows high expression levels 
in the stomach, lung, colon, heart and kidney (Figure 5C). In addition, tbKLF6 is highly expressed in the heart and lowly expressed in the spleen and colon (Figure 5D). TbKLF11 is highly expressed in the heart but lowly expressed in the spleen and lung (Figure 5E). TbKLF12 is highly expressed in the heart and lowly expressed in the lung and colon (Figure 5F). Overall, these tbKLFs are ubiquitously expressed in different tissues, while some factors show tissue-specific expression patterns.

Then, we examined the protein levels of tbKLF2, 3, 5, 7 and 11 in the liver, heart, spleen, lung, kidney, stomach and colon by Western blotting based on the availability of antibodies (Figure 6). KLF2 is ubiquitously expressed in all tested tissues (Figure 6A). The KLF3 protein level is highly detected in the liver and colon but almost undetectable in the heart (Figure 6A). Both KLF5 and 7 are expressed at high levels in the liver and kidney (Figure 6). High protein expression levels of KLF11 were detected in the heart and colon (Figure 6B). Thus, each tbKLF shows a unique expression pattern at both the mRNA and protein levels. They are extensively expressed in various tissues but each member shows a tissue-specific expression pattern. Notably, compared to the corresponding mRNA levels of tbKLF3, 5 and 11, the protein expression pattern is not always consistent with the mRNA expression pattern.

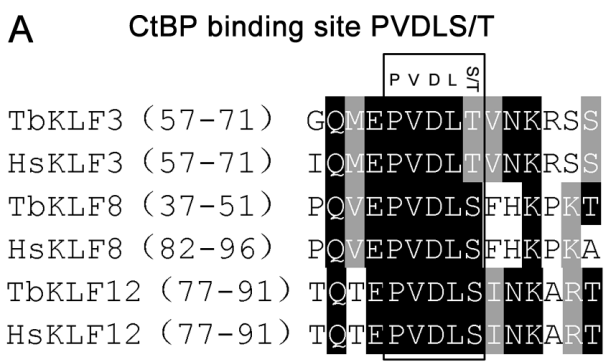

B Sin $3 A$ binding site $A A / V X X L$
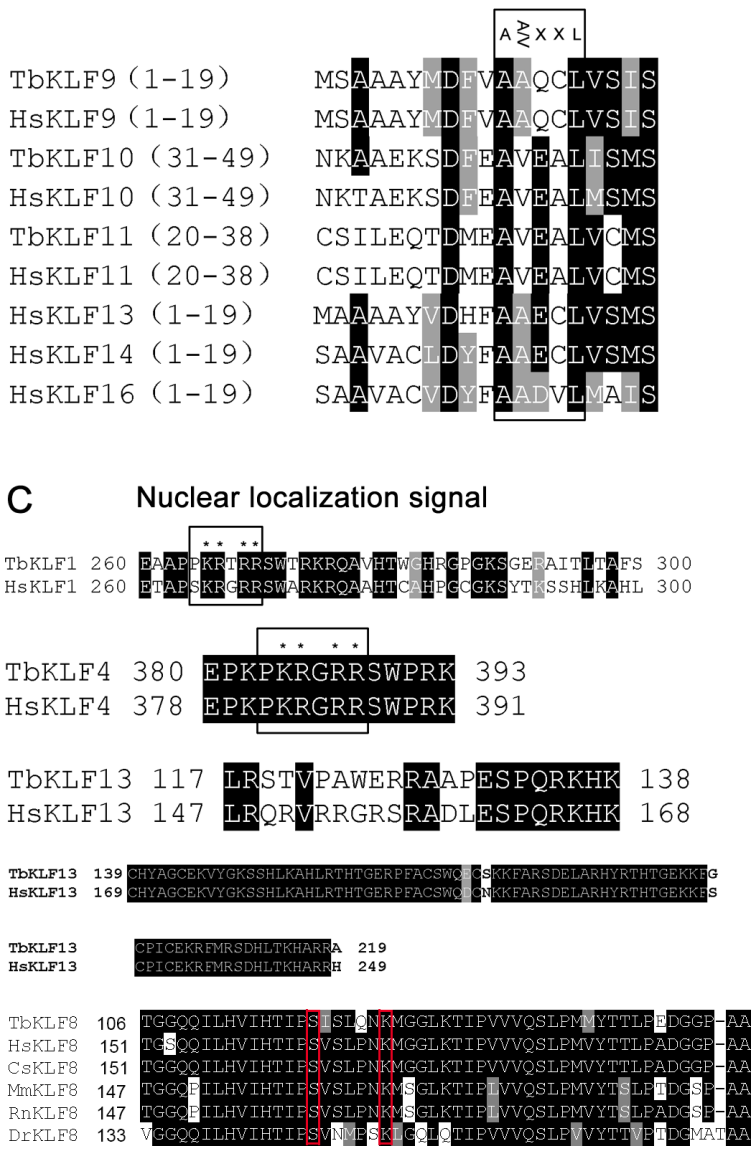

Figure 3: Sequence alignment of conserved CtBP binding motifs, Sin3A binding motifs, and nuclear localization signals in KLFs. (A) CtBP binding motif PVDLS/T in KLF3, 8 and 12. (B) Sin3A binding motif AA/VXXL in KLF9, 10, 11, 13,14 and 16. (C) Nuclear localization signal sequence in KLF1, 4, 5, 8 and 13. 


\section{TbKLF5 promotes cell proliferation like hKLF5}

To compare the functions of tbKLFs and hKLFs, we took KLF5 as an example and compared the proproliferation function of tbKLF5 and hKLF5 in NIH3T3 cells. KLF5 has been shown to promote NIH3T3 cell proliferation in vitro [71]. As shown in Figure 6C, when tbKLF5 and hKLF5 were overexpressed in NIH3T3 cells, both tbKLF5 and hKLF5 significantly and equally promote cell proliferation compared to the vector control. These results suggest that tbKLF5 functions similarly to hKLF5 in terms of promoting cell proliferation. In another word, the pro-proliferation function of KLF5 is conserved between tree shrews and human beings.

\section{DISCUSSION}

KLF transcription factors belong to a large zinc finger domain family. In mammals, 17 KLF members have been implicated in many physiological and pathological processes [4]. Elucidating the structures, functions and expression patterns of the KLF members is important for understanding their essential roles in normal tissue development and diseases. Considering that tree shrews are becoming novel disease animal models, it is important to understand the biology of tree shrews at the molecular level. However, KLFs in the tree shrew have not been investigated previously.

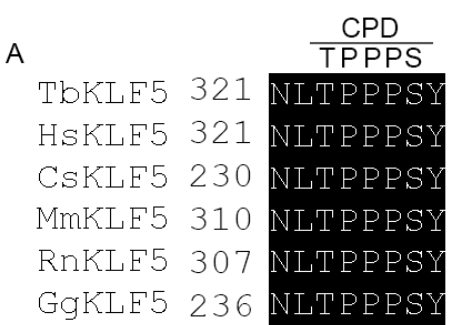

C

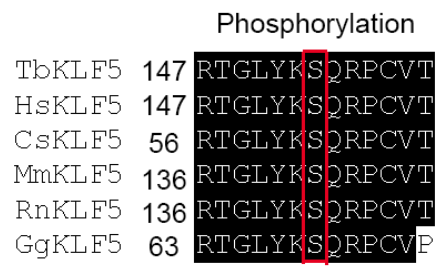

In this study, we first identified 17 tbKLF protein sequences and defined their evolutionary status compared to other species. Then, we analyzed the conservation of their functional domains, including the ZF domain, CtBP binding site, Sin3A binding site and NLS. In addition, we analyzed the conservation of known KLF5 posttranslational motifs or sites in the tree shrew. Finally, we examined the mRNA and protein expression patterns of several KLFs in different tree shrew tissues.

A phylogenetic analysis showed that $K L F$ genes in mammals could be divided into two large groups [1]. In porcine, two groups were further divided into three subgroups according to their clusters in the phylogenetic tree [33]. In addition to porcine, similar KLF subgroups were also classified in humans [31] and mice [32]. As expected, tbKLFs were also divided into the same subgroups according to the phylogenetic analysis, indicating that they might also be functionally conserved among human, mouse, porcine and tree shrew sequences. A phylogenetic tree using tree shrew, human, monkey, rat, mouse, chicken and zebrafish sequences demonstrate that the tbKLF family likely originates from the same ancestor. Though most mammalian KLFs show a similar evolutionary pattern, some tbKLFs, such as KLF1, 11, 13, 16 and 17, have unique evolution pathways. They obviously separate from both primates and rodents on the evolutionary branches. In particular, KLF17 was a distinct member that is distantly related to the other KLFs.
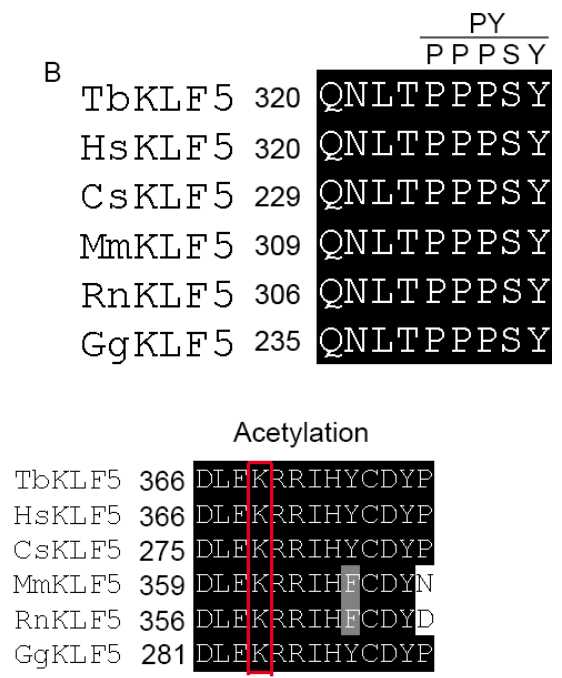

Sumoylation

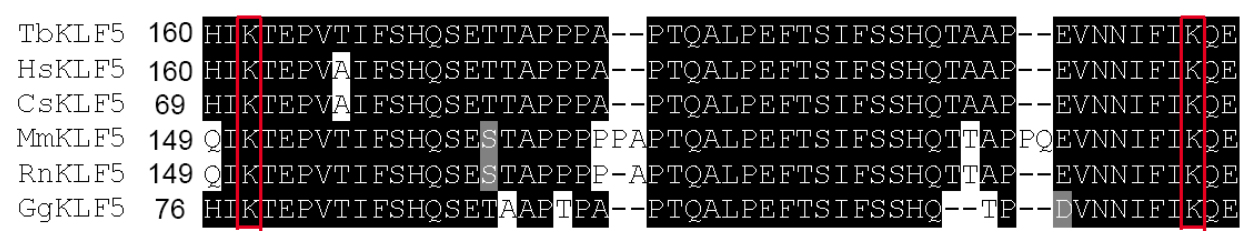

Figure 4: Post-translational modification sequences are conserved in tbKLF5. (A) The Fbw7 binding CPD motif sequence is conserved among tree shrew, human, monkey, mouse, rat and chicken sequences. (B) The WWP1 binding PY motif sequence is conserved among tree shrew, human, monkey, mouse, rat and chicken sequences. (C) The PKC phosphorylation site S153, the acetylation site K369 and two sumoylation sites K162 and K209 are conserved in tree shrew KLF5. 
KLF transcription factors contain highly conserved DNA binding domains at their C-termini and variant $\mathrm{N}$-termini, which interact with cofactors to activate and/ or repress gene transcription. We identified 3 conserved C2H2 ZF domains [30] from all the tbKLFs except tbKLF1 and tbKLF6. It's weird that tbKLF1 and 6 don't have the first ZF domain. This may be caused by mRNA alternative splicing. A phylogenetic tree indicated that the ZF domains are highly conserved among human, mouse and tree shrew proteins. In the N-termini, the CtBP or
Sin3A binding motifs and NLS are also largely conserved. These conserved sequence regions may be essential for their functions.

KLF5 is an important transcription factor associated with many human cancers, such as breast cancer [64, 65, 72], gastric cancer [73], colorectal cancer [74], bladder cancer [75] and prostate cancer [76]. Post-translational modifications are vital for regulating KLF5 activity. The alignment results showed that tbKLF5 has conserved CPD and PY motifs for recruiting E3 ubiquitin ligases

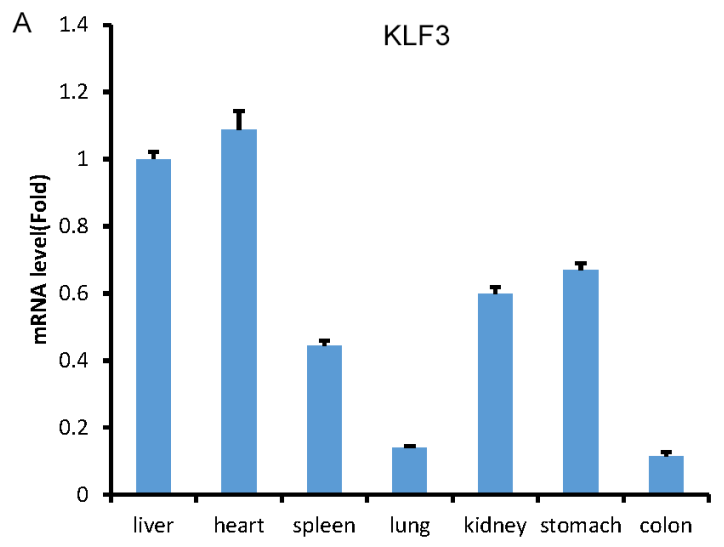

B
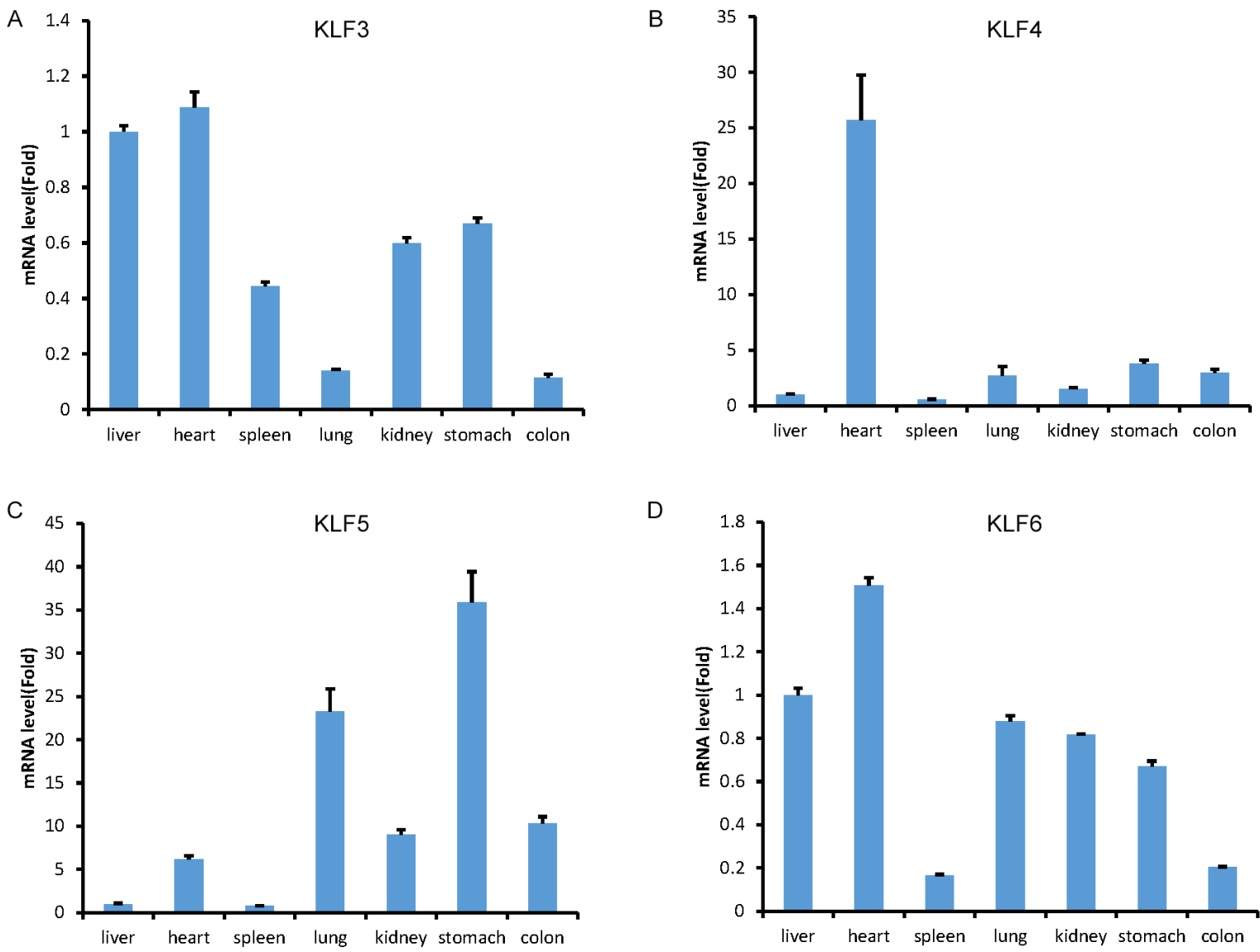

D
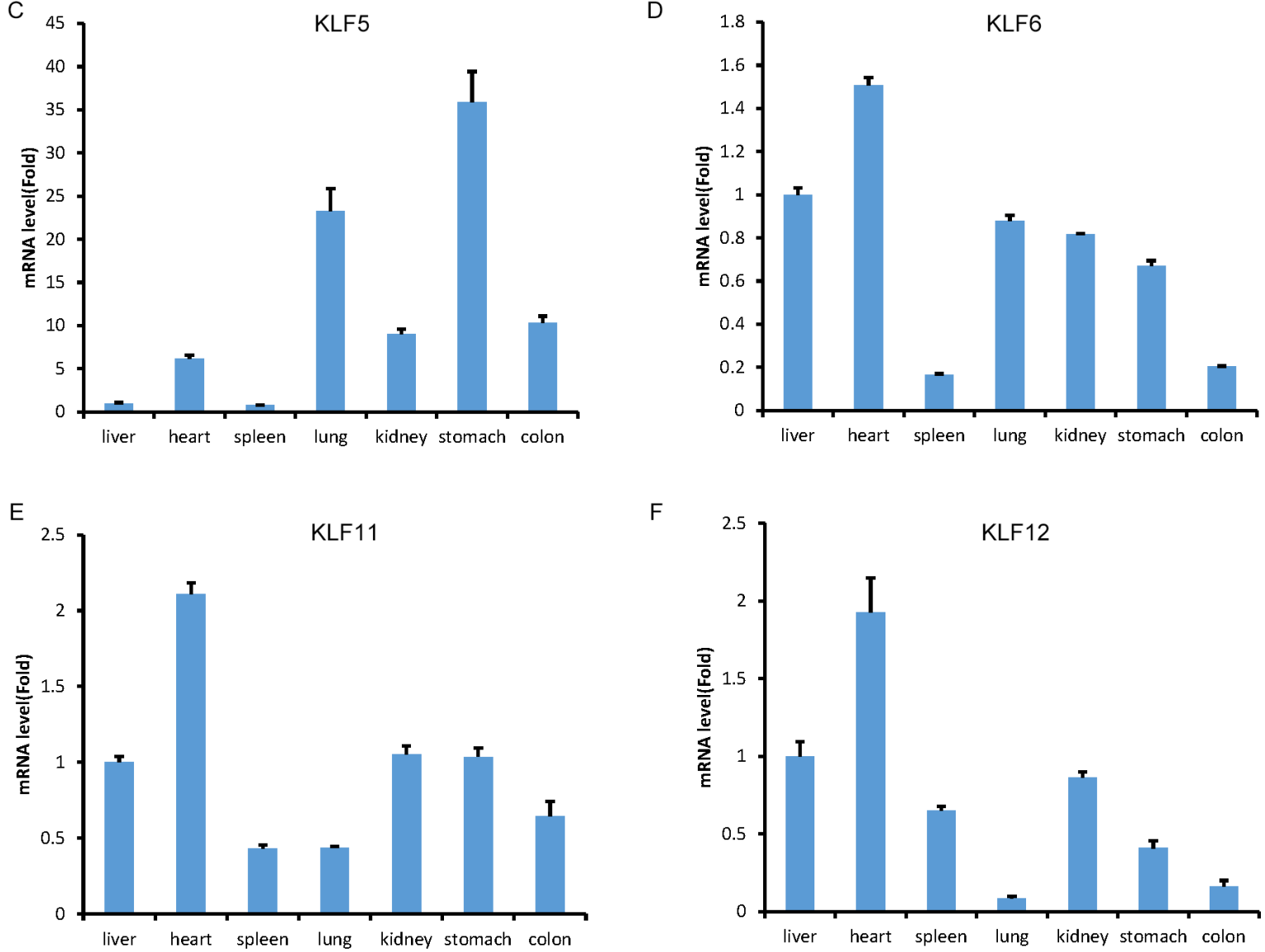

F

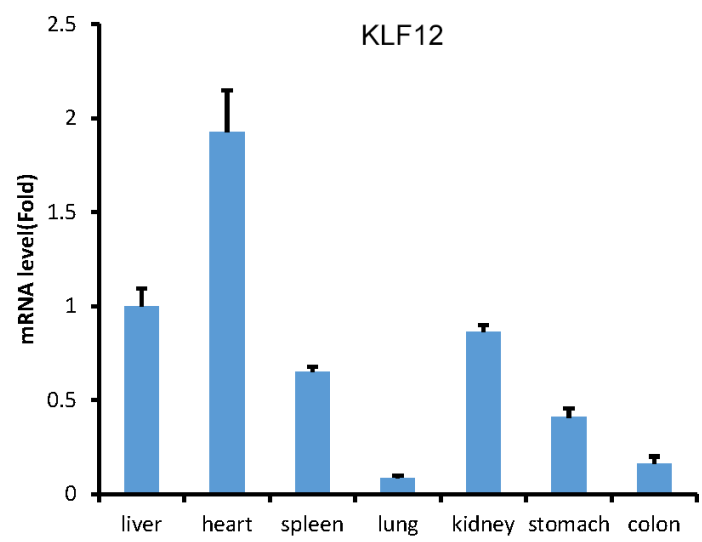

Figure 5: The mRNA expression levels of tree shrew KLF3, 4, 5, 6, 11 and 12 in the liver, heart, spleen, lung, kidney, stomach and colon tissues, as measured by RT-qPCR. The expression level of KLFs in the liver was defined as 1. 
$[3,63]$. Furthermore, tbKLF5 and hKLF5 have the same S153 and S303 sites for phosphorylation, K369 site for acetylation and K162 and K209 site for sumoylation. Importantly, both tbKLF5 and hKLF5 promote NIH3T3 cell proliferation similarly. These results suggest that the tree shrew may serve as an alternative animal model for human diseases related to KLF5. In addition to tbKLF5, it is worth exploring other tbKLF post-transcriptional modifications that are related to many important human diseases.

The expression levels of KLFs in different tissues may indicate their functions in organ development, homeostasis and diseases. In the tree shrew, we determined the relative mRNA and protein levels of several KLFs in the adult liver, heart, spleen, lung, kidney, stomach and colon. The high expression levels of KLF5 mRNA in the lung and colon are consistent with that in humans [77]. TbKLF4 is highly expressed in the heart and modestly expressed in the lung and colon at the mRNA level. However, $m K L F 4$ is not highly expressed in the heart, although it is highly expressed in the lung and colon [78]. Thus, KLF4 may play a role in the maintenance of tree shrew, but not mouse, cardiac function.

The protein levels of tbKLF3, 5 and 11 are not consistent with their mRNA levels in the same tissues. Post-translational modifications may contribute to tbKLF protein expression. Using the KLF5 protein as an example, phosphorylation, acetylation, ubiquitination, and sumoylation are known to change protein levels without affecting mRNA levels $[3,4]$.

In summary, we identified 17 KLF members in the tree shrew and performed a comprehensive phylogenetic analysis. The high phylogenetic conservation in the sequences of tree shrew, human, mouse and other species indicates the functional significance of tbKLFs. Finally, we demonstrated that several tbKLFs are widely expressed in different adult tissues. Our study provides insight for further functional study of the $K L F$ gene family in tree shrews.
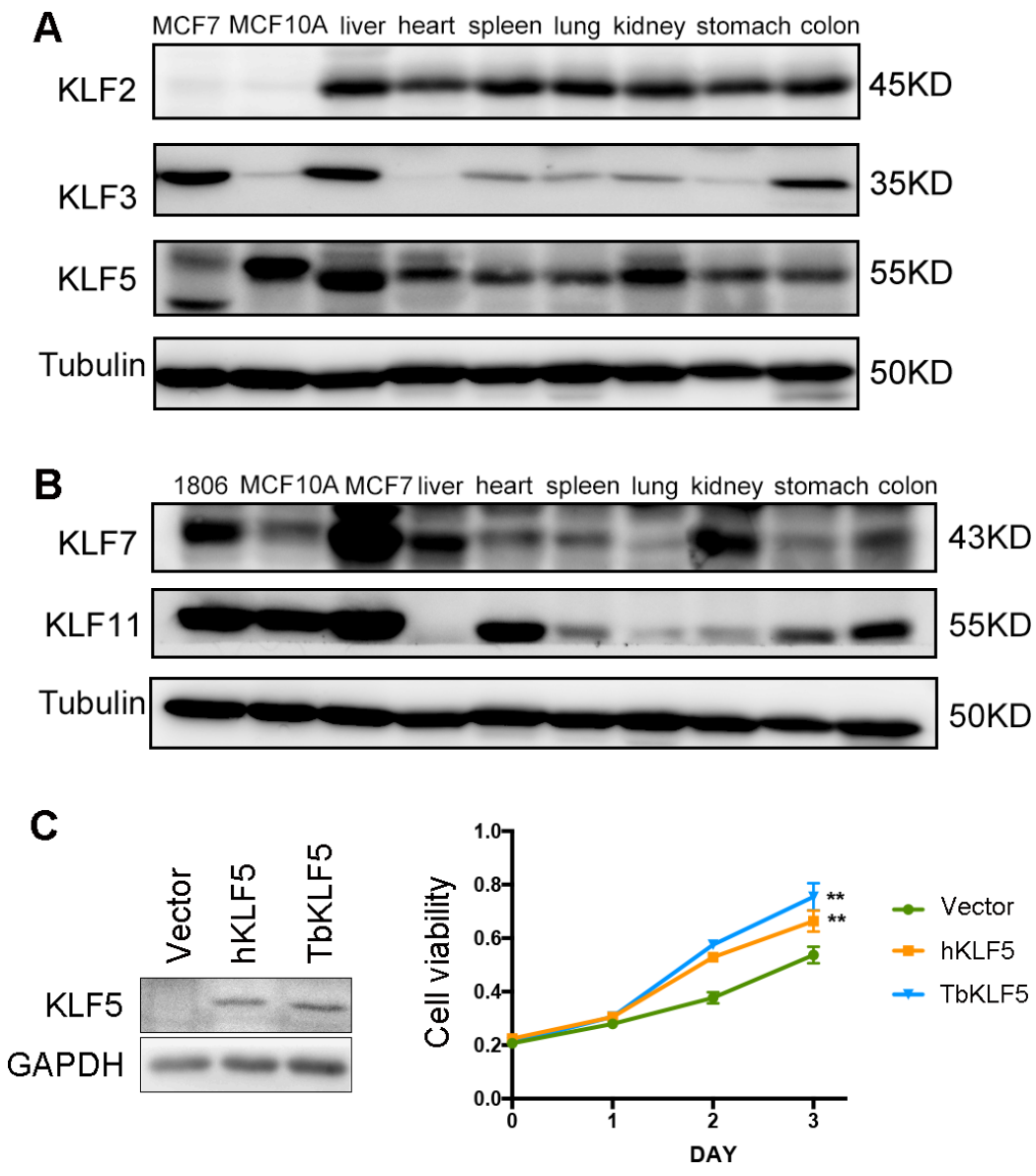

Figure 6: The protein expression levels of tree shrew KLF2, 3, 5, 7 and 11 in different tissues and tbKLF5 promotes cell proliferation like hKLF5. (A) The protein expression levels of tbKLF2, 3, and 5 in different tissues was measured by Western blotting. Tubulin was used as the loading control. Two human breast epithelial cell lines, MCF7 and MCF10A, were used as controls. (B) The protein expression levels of tbKLF7 and 11 in different tissues was measured by Western blotting. Three human breast epithelial cell lines, HCC1806, MCF10A and MCF7, were used as controls. (C) Overexpression of TbKLF5 or hKLF5 in NIH3T3 cells promote cell proliferation. The expression of TbKLF5 or hKLF5 in NIH3T3 cells was measured by Western blotting (Left panel). Overexpression of TbKLF5 or hKLF5 promote NIH3T3 cell proliferation in the course of three days, as measured by the SRB assay (Right panel). ${ }^{* *} p<0.01$. 


\section{MATERIALS AND METHODS}

\section{Identification of tbKLF gene sequences}

The genome sequence of the tree shrew was completed by second-generation sequencing technology described previously [54]. The coding sequences of KLF6 were obtained directly from the tree shrew database (http://www.treeshrewdb.org/), which was built and supported by the Kunming Institute of Zoology, Chinese Academy of Science [55]. The rest of complete coding sequences of tbKLF1, 3, 4, 7, 8, 10-16 and 17 were retrieved from the NCBI database (http://www.ncbi. nlm.nih.gov). Because tbKLF2, 5, 9 have neither been identified nor predicted, we cloned and identified the CDSs of tbKLF2, 5, 9.

The F2 outbreed Chinese tree shrews were fed in the animal center of Kunming Institute of Zoology, Chinese Academy of Science. The liver, heart, spleen, lung, kidney, stomach and colon were harvested from a six-monthold adult female tree shrew using a tissue homogenizer (TIANGEN, OSE-Y20). Total RNA was extracted from different tissues using TRIzol (Life Technologies, Massachusetts, USA). cDNAs were generated using the Revert Aid First Strand cDNA Synthesis Kit (Thermo Scientific, Massachusetts, USA). cDNAs from the lung and liver were used as PCR templates, and PCR reactions were conducted using standard reaction conditions. The PCR primers for tsKLF2, 5, and 9 were designed according to their homologous sequences from human, mouse and pig. The PCR primers were as follows: tbKLF2-F: 5'-CGTCCT TCTCCACTTTCGCC-3'; tbKLF2-R: 5'-CAGGTGGTCA GAGCGTGAG-3'; tbKLF5-F: 5'-ATGGCTACGCGGGT GTTGACCATGAGCGCCCGCCTGGG-3'; tbKLF5-R: 5'-TCAGTTCTGGTGCCTCTTCAT-3'; tbKLF9-F: 5'-AT GTCCGCGGCCGCCTACATGGACT-3'; and tbKLF9-R: 5'-TCACAAAGGGTTGGCCAGCGCCTTT-3'. The target genes were cloned into the pGEM-T vector (Promega, Cat\#A3600, Shanghai) and sequenced. The sequences were aligned to their human and mouse homologs and then deposited into GenBank (accession numbers: KT948683, KT948685 and KT948684). All GenBank accession numbers of the 17 tbKLFs are listed in Table 1.

\section{Comparative and phylogenetic analysis}

The KLF coding sequences from various species, including human, monkey, rat, mouse, zebrafish, and chicken, were obtained from GenBank (accession numbers are listed in Supplementary Table S2). Multiple and pairwise alignment of the whole amino acid sequences among or between KLF orthologs were conducted using the Clustal X2.1 program. After comparative analysis, Some conserved domains,including the ZF domain, CtBP binding, Sin3 A binding domain and NLS, were then marked by the BoxShade (http://www.ch.embnet.org/software/ BOX_form.html).

The phylogenetic analysis was performed by MEGA5 (http://www.megasoftware.net) using the Maximum Likelihood (ML) method [56] and NeighborJoining (NJ) [57] method with bootstrapping analyses [58]. In brief, we firstly made complement alignment of the whole amino acid sequences of KLF family among seven lineages, including human, monkey, tree shrew, rat, mouse, chicken and zebrafish and then eliminated mismatch sequences and gaps at both ends. This data containing 116 amino acid sequences was used to reconstruct phylogenetic tree by both ML and NJ methods on MEGA5, with the bootstrap test value setting as 1000 .

\section{RT-qPCR}

Real-time qPCR was used to examine the expression patterns of $t b K L F s$ at the RNA level. cDNAs from the seven tissues were used as templates. SYBR Select Master Mix (ABI, Cat\#4472908, Carlsbad) was used for qPCR in an ABI-7900 HT. The cycling condition was $95^{\circ} \mathrm{C}$ for $2 \mathrm{~min}, 95^{\circ} \mathrm{C}$ for $15 \mathrm{~s}$, and $60^{\circ} \mathrm{C}$ for $1 \mathrm{~min}$ for 40 cycles. The $\Delta \Delta \mathrm{Ct}$ method was used to analyze $K L F$ mRNA levels, and $b$-actin was used as the loading control. Primers for qPCR were designed to skip exons to avoid genomic DNA contamination. The primer sequences were as follows:

KLF3 F: 5'- GCTCCCATTTGAAAGCACAC -3'; R: 5'- TTCGTCAGACCGAGCAAAC -3'; KLF4 F: 5'- GCGAGTCTGACATGGCTGT -3'; R: 5'- CTCCGTTCTCCAGGTCTGTG -3'; KLF5 F: 5'- CGCATCCACTACTGCGATTA -3'; R: 5'- TGAGTCCTCAGGTGAGCTTTT -3'; KLF6 F: 5'- AAAGCTCCCACTTGAAAGCA -3'; R: 5'- ACTTCTTGCAAAACGCCACT -3'; KLF11 F: 5'- TTCCCACCTTAAGGCTCATC -3'; R: 5'- AACTTCTTCTCCCCTGTGTGAG -3'; KLF12 F: 5'- ACTATTGTCGTGCCGCTTTT -3'; R: 5'- AAGGTCACATTTGGCAGGTC -3'; Actin F: 5'- CATCCGTAAGGACCTGTATG - $3^{\prime}$; and R: 5'- GTAACAGTCCGCCTAGAAGC -3'.

\section{Western blotting}

Fresh tissues of the liver, heart, spleen, lung, kidney, stomach and colon were harvested in lysis buffer (50 mM Tris- $\mathrm{HCl}$ (pH 7.4), $150 \mathrm{mM} \mathrm{NaCl}, 1 \mathrm{mM}$ EDTA, $1 \%$ Triton X-100) with $1 \%$ protease inhibitor cocktail (Sigma P8340, Shanghai). The Bio-Rad Dc Protein Assay (BIO-RAD, Hercules) was used to quantify protein concentration. The following antibodies were used: KLF2 (ABNOVA, Cat\#H00010365-A01, Taipei), KLF3 (Abcam, Cat\#ab49221-100, Cambridge), KLF5 (homemade), KLF7 (Abcam, Cat\#ab58306-100, Cambridge) and KLF11 (Abcam, Cat\#ab65029-100, Cambridge) and Tubulin (Sigma, Cat\#T5168, Shanghai). 
All these antibodies have been validated for WB. All experimental protocols were approved by Kunming Institute of Zoology, Chinese Academy of Sciences, animal welfare and ethical committee.

\section{Cell culture}

NIH3T3 was purchased from the American Type Culture Collection (ATCC). NIH3T3 cells were cultured in DMEM containing $10 \%$ fetal bovine serum at $37^{\circ} \mathrm{C}$ in humidified incubator with $5 \% \mathrm{CO}_{2}$.

\section{TbKLF5 and hKLF5 overexpression plasmids}

TbKLF5 cDNA was amplified by PCR using tree shrew uterus cDNA as a template. The primer sequences are:

Forward 5'-CGGGATCCATGGCTACGCGGGTGTTG ACCATGAGCGCCCGCCTGGG-3'

Backward 5'-CGGAATTCTCAGTTCTGGTGCCTCTT CAT-3'. The PCR products were subcloned into the pBabe-puro retroviral vector by using Bam HI and Eco RI restriction enzyme cleavage sites. The cloned TbKLF5 was confirmed by sequencing. hKLF5 was previously cloned into the same vector.

\section{Cell proliferation assays}

The Sulforhodamine B (SRB, Sigma, St. Louis, $\mathrm{MO}$ ) assays were performed to measure cell proliferation. NIH3T3 cells were transfected with expression plasmids of hKLF5, TbKLF5, or empty vector. The expression of KLF5 was confirmed by Western blotting. Forty-eight hours after transfection, 5,000 NIH3T3 cells were seeded in 48-well plates in triplicate. The cells were fixed with $200 \mathrm{ml}$ of $10 \%$ trichloroacetic acid (TCA, Sigma, St. Louis, MO) for $60 \mathrm{~min}$ and then washed 5 times with deionized water and air dried. The cells were stained with $100 \mathrm{ml}$ of $0.4 \%(\mathrm{~W} / \mathrm{V}) \mathrm{SRB}$ in acetic acid for $5 \mathrm{~min}$. Then the plates were washed 5 times with $1 \%$ acetic acid and dried. Following that, $150 \mathrm{ml}$ of $10 \mathrm{mM}$ Tris base was added to each well. Finally, optical densities were measured on an automated spectrophotometric plate reader at a single wavelength of $530 \mathrm{~nm}$. The results are presented as the means \pm the standard deviations of three independent experiments. Student's tests were used to compare pairs of variables. Results were considered statistically significant at the level of $* p<0.05$ or $* *_{p}<0.01$.

\section{ACKNOWLEDGMENTS}

This study was supported by grants from the National Natural Science Foundation of China (81325016 and 81120108019 to Chen, C., and 31560613 to He, B. L. ).

\section{CONFLICTS OF INTEREST}

None.

\section{Authors' contributions}

SM, GGZ and LWJ carried out the most experiments and drafted the manuscript. ZF and FY helped data analysis. LWJ, XHJ, XJ and HBL collected tree shrew tissues. CC participated in the design of the study and revised the manuscript. All authors read and approved the final manuscript.

\section{REFERENCES}

1. Kaczynski J, Cook T, Urrutia R. Sp1- and Kruppel-like transcription factors. Genome biology. 2003; 4:206.

2. Presnell JS, Schnitzler CE, Browne WE. KLF/SP Transcription Factor Family Evolution: Expansion, Diversification, and Innovation in Eukaryotes. Genome Biology and Evolution. 2015; 7:2289-2309.

3. Dong JT, Chen C. Essential role of KLF5 transcription factor in cell proliferation and differentiation and its implications for human diseases. Cell Mol Life Sci. 2009; 66:2691-2706.

4. McConnell BB, Yang VW. Mammalian Kruppel-like factors in health and diseases. Physiol Rev. 2010; 90:1337-1381.

5. Shi Y, Desponts C, Do JT, Hahm HS, Scholer HR, Ding S. Induction of pluripotent stem cells from mouse embryonic fibroblasts by Oct4 and Klf4 with small-molecule compounds. Cell Stem Cell. 2008; 3:568-574.

6. Nandan MO, Yang VW. The role of Kruppel-like factors in the reprogramming of somatic cells to induced pluripotent stem cells. Histol Histopathol. 2009; 24:1343-1355.

7. Groenendijk BC, Hierck BP, Gittenberger-De Groot AC, Poelmann RE. Development-related changes in the expression of shear stress responsive genes KLF-2, ET-1, and NOS-3 in the developing cardiovascular system of chicken embryos. Developmental dynamics. 2004; 230:57-68.

8. Zahlten J, Steinicke R, Bertrams W, Hocke AC, Scharf S, Schmeck B, Witzenrath M, Hammerschmidt S, Suttorp N, Hippenstiel S. TLR9- and Src-dependent expression of Krueppel-like factor 4 controls interleukin-10 expression in pneumonia. European Respiratory Journal. 2013; 41:384-391.

9. Katz JP, Perreault N, Goldstein BG, Actman L, McNally SR, Silberg DG, Furth EE, Kaestner KH. Loss of Klf4 in mice causes altered proliferation and differentiation and precancerous changes in the adult stomach. Gastroenterology. 2005; 128:935-945.

10. Matsumoto N, Kubo A, Liu H, Akita K, Laub F, Ramirez F, Keller G, Friedman SL. Developmental regulation of yolk sac hematopoiesis by Kruppel-like factor 6. Blood. 2006; 107:1357-1365. 
11. Subramaniam M, Gorny G, Johnsen SA, Monroe DG, Evans GL, Fraser DG, Rickard DJ, Rasmussen K, van Deursen JM, Turner RT, Oursler MJ, Spelsberg TC. TIEG1 null mouse-derived osteoblasts are defective in mineralization and in support of osteoclast differentiation in vitro. Molecular and cellular biology. 2005; 25:1191-1199.

12. Feinberg MW, Wara AK, Cao Z, Lebedeva MA, Rosenbauer F, Iwasaki H, Hirai H, Katz JP, Haspel RL, Gray S, Akashi K, Segre J, Kaestner KH, et al. The Kruppel-like factor KLF4 is a critical regulator of monocyte differentiation. Embo j. 2007; 26:4138-4148.

13. Vu TT, Gatto D, Turner V, Funnell AP, Mak KS, Norton LJ, Kaplan W, Cowley MJ, Agenes F, Kirberg J, Brink R, Pearson RC, Crossley M. Impaired B cell development in the absence of Kruppel-like factor 3. Journal of immunology (Baltimore, Md : 1950). 2011; 187:5032-5042.

14. Shindo T, Manabe I, Fukushima Y, Tobe K, Aizawa K, Miyamoto S, Kawai-Kowase K, Moriyama N, Imai Y, Kawakami H, Nishimatsu H, Ishikawa T, Suzuki T, et al. Kruppel-like zinc-finger transcription factor KLF5/BTEB2 is a target for angiotensin II signaling and an essential regulator of cardiovascular remodeling. Nat Med. 2002; 8:856-863.

15. Chin MT. KLF15 and Cardiac Fibrosis: The Heart Thickens. Journal of molecular and cellular cardiology. 2008; 45:165-167.

16. Liao X, Sharma N, Kapadia F, Zhou G, Lu Y, Hong H, Paruchuri K, Mahabeleshwar GH, Dalmas E, Venteclef N, Flask CA, Kim J, Doreian BW, et al. Krüppel-like factor 4 regulates macrophage polarization. The Journal of Clinical Investigation. 2011; 121:2736-2749.

17. Blanchon Lc, Bocco JL, Gallot D, Gachon A-M, Lémery D, Déchelotte P, Dastugue B, Sapin V. Co-localization of KLF6 and KLF4 with pregnancy-specific glycoproteins during human placenta development. Mechanisms of Development. 2001; 105:185-189.

18. Bhattacharya R, Senbanerjee S, Lin Z, Mir S, Hamik A, Wang P, Mukherjee P, Mukhopadhyay D, Jain MK. Inhibition of vascular permeability factor/vascular endothelial growth factor-mediated angiogenesis by the Kruppel-like factor KLF2. The Journal of biological chemistry. 2005; 280:28848-28851.

19. Wara AK, Manica A, Marchini JF, Sun X, Icli B, Tesmenitsky Y, Croce K, Feinberg MW. Bone marrowderived Kruppel-like factor 10 controls reendothelialization in response to arterial injury. Arterioscler Thromb Vasc Biol. 2013; 33:1552-1560.

20. Gray S, Wang B, Orihuela Y, Hong EG, Fisch S, Haldar S, Cline GW, Kim JK, Peroni OD, Kahn BB, Jain MK. Regulation of gluconeogenesis by Kruppel-like factor 15 . Cell Metab. 2007; 5:305-312.

21. Yang Y, Goldstein BG, Chao HH, Katz JP. KLF4 and KLF5 regulate proliferation, apoptosis and invasion in esophageal cancer cells. Cancer Biol Ther. 2005; 4:1216-1221.
22. Prosdocimo DA, Anand P, Liao X, Zhu H, Shelkay S, Artero-Calderon P, Zhang L, Kirsh J, Moore DV, Rosca MG, Vazquez E, Kerner J, Akat KM, et al. Kruppellike Factor 15 Is a Critical Regulator of Cardiac Lipid Metabolism. Journal of Biological Chemistry. 2014; 289:5914-5924.

23. Brey CW, Nelder MP, Hailemariam T, Gaugler R, Hashmi S. Krüppel-like family of transcription factors: an emerging new frontier in fat biology. International Journal of Biological Sciences. 2009; 5:622-636.

24. Swamynathan SK. Kruppel-like factors: three fingers in control. Hum Genomics. 2010; 4:263-270.

25. Quadrini KJ, Bieker JJ. Kruppel-like zinc fingers bind to nuclear import proteins and are required for efficient nuclear localization of erythroid Kruppel-like factor. The Journal of biological chemistry. 2002; 277:32243-32252.

26. Shields JM, Yang VW. Two potent nuclear localization signals in the gut-enriched Kruppel-like factor define a subfamily of closely related Kruppel proteins. The Journal of biological chemistry. 1997; 272:18504-18507.

27. Song A, Patel A, Thamatrakoln K, Liu C, Feng D, Clayberger C, Krensky AM. Functional domains and DNAbinding sequences of RFLAT-1/KLF13, a Kruppel-like transcription factor of activated T lymphocytes. The Journal of biological chemistry. 2002; 277:30055-30065.

28. Mehta TS, Lu H, Wang X, Urvalek AM, Nguyen K-HH, Monzur F, Hammond JD, Ma JQ, Zhao J. A unique sequence in the $\mathrm{N}$-terminal regulatory region controls the nuclear localization of KLF8 by cooperating with the C-terminal zinc-fingers. Cell Res. 2009; 19:1098-1109.

29. Schuh R, Aicher W, Gaul U, Côte S, Preiss A, Maier D, Seifert E, Nauber U, Schröder C, Kemler R, Jäckle H. A conserved family of nuclear proteins containing structural elements of the finger protein encoded by Krüppel, a Drosophila segmentation gene. Cell. 1986; 47:1025-1032.

30. Suske G, Bruford E, Philipsen S. Mammalian SP/KLF transcription factors: bring in the family. Genomics. 2005; 85:551-556.

31. Zhang P, Basu P, Redmond LC, Morris PE, Rupon JW, Ginder GD, Lloyd JA. A functional screen for Krüppel-like factors that regulate the human $\gamma$-globin gene through the CACCC promoter element. Blood Cells, Molecules, and Diseases. 2005; 35:227-235.

32. Ravasi T, Huber T, Zavolan M, Forrest A, Gaasterland T, Grimmond S, Hume DA. Systematic characterization of the zinc-finger-containing proteins in the mouse transcriptome. Genome Res. 2003; 13:1430-1442.

33. Chen Z, Lei T, Chen X, Zhang J, Yu A, Long Q, Long H, Jin D, Gan L, Yang Z. Porcine KLF gene family: Structure, mapping, and phylogenetic analysis. Genomics. 2010; 95:111-119.

34. Basu P, Sargent TG, Redmond LC, Aisenberg JC, Kransdorf EP, Wang SZ, Ginder GD, Lloyd JA. Evolutionary conservation of KLF transcription factors and 
functional conservation of human $\gamma$-globin gene regulation in chicken. Genomics. 2004; 84:311-319.

35. Oates AC, Pratt SJ, Vail B, Yan Y, Ho RK, Johnson SL, Postlethwait JH, Zon LI. The zebrafish klf gene family. Blood. 2001; 98:1792-1801.

36. Seetharam A, Bai Y, Stuart GW. A survey of well conserved families of $\mathrm{C} 2 \mathrm{H} 2$ zinc-finger genes in Daphnia. BMC Genomics. 2010; 11:276.

37. Zhang J, Bakheet R, Parhar RS, Huang C-H, Hussain MM, Pan X, Siddiqui SS, Hashmi S. Regulation of Fat Storage and Reproduction by Krüppel-Like Transcription Factor KLF3 and Fat-Associated Genes in Caenorhabditis elegans. Journal of Molecular Biology. 2011; 411:537-553.

38. Pei J, Grishin NV. C2H2 zinc finger proteins of the SP/KLF, Wilms tumor, EGR, Huckebein, and Klumpfuss families in metazoans and beyond. Gene. 2015; 573:91-99.

39. Xu L, Zhang Y, Liang B, Lu LB, Chen CS, Chen YB, Zhou JM, Yao YG. [Tree shrews under the spot light: emerging model of human diseases]. Dong wu xue yan jiu = Zoological research / "Dong wu xue yan jiu" bian ji wei yuan hui bian ji. 2013; 34:59-69.

40. Yongtang Zheng YY, Lin Xu. Basic biology and disease models of tree shrews. (Yunnan Science and Technology Press. 2014.

41. Jobling AI, Wan R, Gentle A, Bui BV, McBrien NA. Retinal and choroidal TGF- $\beta$ in the tree shrew model of myopia: Isoform expression, activation and effects on function. Experimental Eye Research. 2009; 88:458-466.

42. Ishiko S, Yoshida A, Mori F, Abiko T, Kitaya N, Kojima M, Saito K. [Early ocular changes in a tree shrew model of diabetes]. Nippon Ganka Gakkai zasshi. 1997; 101:19-23.

43. Wu XY, Li YH, Chang Q, Zhang LQ, Liao SS, Liang B. [Streptozotocin induction of type 2 diabetes in tree shrew]. Dong wu xue yan jiu = Zoological research / "Dong wu xue yan jiu” bian ji wei yuan hui bian ji. 2013; 34:108-115.

44. Schmelting B, Corbach-Söhle S, Kohlhause S, Schlumbohm C, Flügge G, Fuchs E. Agomelatine in the tree shrew model of depression: Effects on stress-induced nocturnal hyperthermia and hormonal status. European Neuropsychopharmacology. 2014; 24:437-447.

45. Wang J, Zhou QX, Lv LB, Xu L, Yang YX. [A depression model of social defeat etiology using tree shrews]. Dong wu xue yan jiu = Zoological research / "Dong wu xue yan jiu" bian ji wei yuan hui bian ji. 2012; 33:92-98.

46. Zhang L, Zhang Z, Li Y, Liao S, Wu X, Chang Q, Liang B. Cholesterol induces lipoprotein lipase expression in a tree shrew (Tupaia belangeri chinensis) model of non-alcoholic fatty liver disease. Scientific reports. 2015; 5:15970.

47. Xu X, Chen H, Cao X, Ben K. Efficient infection of tree shrew (Tupaia belangeri) with hepatitis $\mathrm{C}$ virus grown in cell culture or from patient plasma. Journal of General Virology. 2007; 88:2504-2512.

48. Tsukiyama-Kohara K, Kohara M. Tupaia Belangeri as an Experimental Animal Model for Viral Infection. Experimental Animals. 2014; 63:367-374.
49. Yang C, Ruan P, Ou C, Su J, Cao J, Luo C, Tang Y, Wang Q, Qin H, Sun W, Li Y. Chronic hepatitis B virus infection and occurrence of hepatocellular carcinoma in tree shrews (Tupaia belangeri chinensis). Virology journal. 2015; 12:26.

50. Li Y, Su JJ, Qin LL, Yang C, Luo D, Ban KC, Kensler T, Roebuck B. Chemopreventive effect of oltipraz on AFBinduced hepatocarcinogenesis in tree shrew model. World journal of gastroenterology. 2000; 6:647-650.

51. Xia HJ, He BL, Wang CY, Zhang HL, Ge GZ, Zhang YX, Lv LB, Jiao JL, Chen C. PTEN/PIK3CA genes are frequently mutated in spontaneous and medroxyprogesterone acetateaccelerated 7,12-dimethylbenz(a)anthracene-induced mammary tumours of tree shrews. Eur J Cancer. 2014; 50:3230-3242.

52. Ge GZ, Xia HJ, He BL, Zhang HL, Liu WJ, Shao M, Wang CY, Xiao J, Ge F, Li FB, Li Y, Chen C. Generation and characterization of a breast carcinoma model by PyMT overexpression in mammary epithelial cells of tree shrew, an animal close to primates in evolution. International Journal of Cancer. 2016; 138:642-651.

53. Xia HJ, Chen CS. Progress of non-human primate animal models of cancers. Dong wu xue yan jiu = Zoological research / "Dong wu xue yan jiu" bian ji wei yuan hui bian ji. $2011 ; 32: 70-80$.

54. Fan Y, Huang ZY, Cao CC, Chen CS, Chen YX, Fan DD, He J, Hou HL, Hu L, Hu XT, Jiang XT, Lai R, Lang YS, et al. Genome of the Chinese tree shrew. Nat Commun. 2013; 4:1426.

55. Fan Y, Yu D, Yao YG. Tree shrew database (TreeshrewDB): a genomic knowledge base for the Chinese tree shrew. Scientific reports. 2014; 4:7145.

56. Tamura K, Peterson D, Peterson N, Stecher G, Nei M, Kumar S. MEGA5: Molecular Evolutionary Genetics Analysis Using Maximum Likelihood, Evolutionary Distance, and Maximum Parsimony Methods. Molecular biology and evolution. 2011; 28:2731-2739.

57. Saitou N, Nei M. The neighbor-joining method: a new method for reconstructing phylogenetic trees. Molecular biology and evolution. 1987; 4:406-425.

58. Felsenstein J. Confidence Limits on Phylogenies: An Approach Using the Bootstrap. Evolution. 1985; 39:783-791.

59. Jones DT, Taylor WR, Thornton JM. The rapid generation of mutation data matrices from protein sequences. Computer applications in the biosciences. 1992; 8:275-282.

60. Suske G, Bruford E, Philipsen S. Mammalian SP/KLF transcription factors: Bring in the family. Genomics. 2005; 85:551-556.

61. Xia HJ, Wang CY, Zhang HL, He BL, Jiao JL, Chen CS. Characterization of spontaneous breast tumor in tree shrews (Tupaia belangeri chinenesis). Dong wu xue yan jiu = Zoological research / "Dong wu xue yan jiu" bian ji wei yuan hui bian ji. 2012; 33:55-59.

62. Xia HJ, He BL, Wang CY, Zhang HL, Ge GZ, Zhang YX, Lv LB, Jiao JL, Chen C. PTEN/PIK3CA genes are frequently 
mutated in spontaneous and medroxyprogesterone acetateaccelerated 7,12-dimethylbenz(a)anthracene-induced mammary tumours of tree shrews. European Journal of Cancer. 2014; 50:3230-3242.

63. Zhao D, Zhi X, Zhou Z, Chen C. TAZ antagonizes the WWP1-mediated KLF5 degradation and promotes breast cell proliferation and tumorigenesis. Carcinogenesis. 2012; 33:59-67.

64. Qin J, Zhou Z, Chen W, Wang C, Zhang H, Ge G, Shao M, You D, Fan Z, Xia H, Liu R, Chen C. BAP1 promotes breast cancer cell proliferation and metastasis by deubiquitinating KLF5. Nat Commun. 2015; 6.

65. Jia L, Zhou Z, Liang H, Wu J, Shi P, Li F, Wang Z, Wang C, Chen W, Zhang H, Wang Y, Liu R, Feng J, et al. KLF5 promotes breast cancer proliferation, migration and invasion in part by upregulating the transcription of TNFAIP2. Oncogene. 2016; 35:2040-51.

66. Chen C, Sun X, Guo P, Dong XY, Sethi P, Cheng X, Zhou J, Ling J, Simons JW, Lingrel JB, Dong JT. Human Kruppellike factor 5 is a target of the E3 ubiquitin ligase WWP1 for proteolysis in epithelial cells. The Journal of biological chemistry. 2005; 280:41553-41561.

67. Zhao D, Zheng H-Q, Zhou Z, Chen C. The Fbw7 Tumor Suppressor Targets KLF5 for Ubiquitin-Mediated Degradation and Suppresses Breast Cell Proliferation. Cancer Research. 2010; 70:4728-4738.

68. Zhang Z, Teng CT. Phosphorylation of Kruppel - like factor 5 (KLF5/IKLF) at the CBP interaction region enhances its transactivation function. Nucleic Acids Research. 2003; 31:2196-2208.

69. Li X, Zhang B, Wu Q, Ci X, Zhao R, Zhang Z, Xia S, Su D, Chen J, Ma G, Fu L, Dong JT. Interruption of KLF5 acetylation converts its function from tumor suppressor to tumor promoter in prostate cancer cells. International journal of cancer. 2015; 136:536-546.

70. Oishi Y, Manabe I, Tobe K, Ohsugi M, Kubota T, Fujiu K, Maemura K, Kubota N, Kadowaki T, Nagai R. SUMOylation of Kruppel-like transcription factor 5 acts as a molecular switch in transcriptional programs of lipid metabolism involving PPAR-[delta]. Nat Med. 2008; 14:656-666.
71. Sun R, Chen X, Yang VW. Intestinal-enriched Kruppellike factor (Kruppel-like factor 5) is a positive regulator of cellular proliferation. The Journal of biological chemistry. 2001; 276:6897-6900.

72. Farrugia MK, Sharma SB, Lin CC, McLaughlin SL, Vanderbilt DB, Ammer AG, Salkeni MA, Stoilov P, Agazie YM, Creighton CJ, Ruppert JM. Regulation of anti-apoptotic signaling by Kruppel-like factors 4 and 5 mediates lapatinib resistance in breast cancer. Cell Death Dis. 2015; 6:e1699.

73. Chia N-, Deng N, Das K, Huang D, Hu L, Zhu Y, Lim KH, Lee MH, Wu J, Sam XX, Tan GS, Wan WK, Yu W, et al. Regulatory crosstalk between lineage-survival oncogenes KLF5, GATA4 and GATA6 cooperatively promotes gastric cancer development. Gut. 2015; 64:707-719.

74. Ruiz de Sabando A, Wang C, He Y, García-Barros M, Kim J, Shroyer KR, Bannister TD, Yang VW, Bialkowska AB. ML264-a novel small-molecule compound that potently inhibits growth of colorectal cancer. Molecular Cancer Therapeutics. 2015; 15:72-83.

75. Gao Y, Wu K, Chen Y, Zhou J, Du C, Shi Q, Xu S, Jia J, Tang X, Li F, Hui K, He D, Guo P. Beyond proliferation: KLF5 promotes angiogenesis of bladder cancer through directly regulating VEGFA transcription. Oncotarget. 2015; 6:43791-805. doi: 10.18632/oncotarget.6101.

76. Li X, Zhang B, Wu Q, Ci X, Zhao R, Zhang Z, Xia S, Su D, Chen J, Ma G, Fu L, Dong J-T. Interruption of KLF5 acetylation converts its function from tumor suppressor to tumor promoter in prostate cancer cells. International Journal of Cancer. 2015; 136:536-546.

77. Shi H, Zhang Z, Wang X, Liu S, Teng CT. Isolation and characterization of a gene encoding human Kruppel-like factor 5 (IKLF): binding to the CAAT/GT box of the mouse lactoferrin gene promoter. Nucleic Acids Research. 1999; 27:4807-4815.

78. Shields JM, Christy RJ, Yang VW. Identification and characterization of a gene encoding a gut-enriched Kruppellike factor expressed during growth arrest. The Journal of biological chemistry. 1996; 271:20009-20017. 